\title{
An empirical analysis of online price dispersion in the Italian airline industry
}

\author{
Paolo Roma* and Fabio Zambuto \\ DICGIM - Management and Economics Research Group, \\ Università degli Studi di Palermo, \\ Viale delle Scienze, 90128, Palermo, Italy \\ Email: paolo.roma@unipa.it \\ Email: fabio.zambuto@unipa.it \\ *Corresponding author
}

\section{Gandolfo Dominici}

SEAS - Polytechnic School, Università degli Studi di Palermo, Viale delle Scienze, 90128, Palermo, Italy

Email: gandolfo.dominici@unipa.it

\begin{abstract}
Firms operating in the electronic marketplace set and adjust prices to affect demand and profitability. In service markets, such as airline markets, different prices are commonly offered by diverse firms to accommodate to a variety of market segments having particular sets of consumer attitudes. This variation in prices is the price dispersion and is based on market distinctiveness deriving from customer heterogeneity as well as the peculiar competition in the specific market arena. In this paper we use a panel dataset from the Italian airline market to investigate the role of competition and different online channels in the emergence of price dispersion. Specifically, we examine the unclear role of competition in price dispersion with novel data collected from different online channels, namely direct and Online Travel Agency (OTA) channels. We find that price dispersion is higher in routes where competition is higher even in presence of only one segment, namely the business segment. Our results also show that price dispersion significantly differs across different types of online channels.
\end{abstract}

Keywords: price dispersion; online distribution channels; airline industry; econometric analysis.

Reference to this paper should be made as follows: Roma, P., Zambuto, F. and Dominici, G. (2015) 'An empirical analysis of online price dispersion in the Italian airline industry', Int. J. Electronic Marketing and Retailing, Vol. 6, No. 4, pp.339-358.

Biographical notes: Paolo Roma is a Assistant Professor of Marketing at the University of Palermo, Italy. He received his $\mathrm{PhD}$ in Industrial Engineering and Management from the same university in 2009. He has been a Visiting Scholar at the University of California at Davis, University of Pittsburgh, and Toulouse School of Economics. His research focuses on topics at the interface between marketing and operations management, such as online distribution channel management, online pricing, mobile app market, and innovative business 
models on the internet. Outlets of his research include Operations Research, Production and Operations Management, International Journal of Production Economics among others.

Fabio Zambuto is a Post-Doctoral Research Fellow at the University of Palermo, Italy. He received his $\mathrm{PhD}$ in Industrial Engineering and Management from the same university in 2014. He has been a Visiting Scholar at the Rensselaer Polytechnic Institute, USA. His research focuses on strategic management and innovation. Outlets of his research include Advances in Strategic Management, Managerial and Decision Economics among others.

Gandolfo Dominici is an Associate Professor of Marketing at the Department SEAS of the University of Palermo (Italy). He is the Scientific Director of the Business Systems Laboratory. He is a board member of the World Organisation of Systems and Cybernetics (WOSC), of the International Society for the Systems Sciences (ISSS) and of the Consorzio Universitario di Economia Industriale e Manageriale (CUEIM). He is the author of more than 65 published articles and books. He is the Editor-in-Chief of three and member of the editorial board of 13 international journals. His main research interests are: marketing, e-marketing, new product development, systems thinking and organisational cybernetics.

\section{Introduction}

Companies operating in the electronic market set and adjust prices to control demand and profitability (Dominici, 2009a, 2009b). In airline tickets market different prices are commonly offered by diverse firms to accommodate to a variety of market segments having specific sets of customers' price sensitiveness. This variation in prices is the price dispersion and is based on market distinctiveness deriving from customer heterogeneity as well as the peculiar competition in the specific market arena. Therefore, to deeper understand how firms can better regulate prices it is pivotal to analyse the effects of some important features of market competition and structure such as price dispersion. Today, in the digital era, customers are increasingly informed, thus knowing the occurrence of exploitable market imperfections has relevant implications for implementing effective pricing strategies and is significant for the viability of firms (Gailey et al., 2012).

In particular, textbook microeconomic theory asserts that price dispersion, to be intended as a measure of price variations in the market, should be lower in markets characterised by higher competition, essentially due to the fact that firms lose their ability to set prices over marginal costs as they approach the ideal perfect competition environment. In this vein, both in the academia and industry world, some have speculated that, due to the increasing price and product information availability, internet and the e-commerce would have fostered higher competition and, eventually, led to pricing consistent with the prediction of the 'law of one price' (Clemons et al., 2002; Baye et al., 2004; Gerardi and Shapiro, 2009; Dominici, 2009a). However, in addition to the traditional effect of competition, some economists have actually pointed out that a reverse effect of competition might actually exist. Essentially, competition might lead to an increase in price dispersion. Specifically, this opposite effect will be likely to occur when firms can price discriminate between segments of consumers characterised by high price sensitivity and low brand loyalty and segments of consumers characterised by low 
price sensitivity and high brand loyalty. In the travel industry, these two macro-segments consist of leisure and business travellers, respectively. As argued by these economists, in presence of such heterogeneous environment, an increase in competition has the effect of reducing, and to some extent aligning, the prices to those segments who are intrinsically price sensitive and less loyal, while leaving prices to less price sensitive and loyal segments almost unchanged due to brand loyalty itself (Borenstein, 1985; Holmes, 1989). Based on this argument, the overall result is that the gap between prices offered to the two types of segments increases with competition, thus driving the price dispersion up. In line with such theoretical argument, often referred to as brand loyalty theory (Gerardi and Shapiro, 2009), a number of studies have demonstrated that, in offline and, especially, online markets, higher price dispersion may be associated with higher market competition (Borenstein and Rose, 1994; Orlov, 2011; Stavins, 2001; Giaume and Guillou, 2004). The emergence of two controversial theories, both supported by empirical evidence, suggests that the influence of competition on price dispersion is not as trivial as one might think at first blush. In fact, these theories reveal that, in general, contrasting competitive dynamics exist behind the impact of competition on the extent of price variability.

The relationship between competition and price dispersion has been analysed in a variety of offline as well as online markets. In this regard, the airline industry has certainly received the widest attention. This is because of several important features characterising such industry. First, the airline industry has experienced numerous important changes in the last decades, ranging from the liberalisation and the entry of low cost carriers in numerous countries to the emergence of e-commerce and online travel agents (OTAs), which have drastically impacted the market structure in terms of competition and cooperation, degree of product differentiation and demand characteristics. Second, price discrimination can be implemented in this market, as there exist customers, i.e., leisure and business travellers, certainly having different price elasticities of demand, and being somehow identifiable with the help of mechanisms such as advance selling, loyalty programs, non-refundable tickets. As discussed above, this feature is essential to the emergence of the brand loyalty effect. Finally, the relevance of the industry itself and the relative impact on the economy, populations and governments within and across countries justify the interest researchers have reserved to the issue of price dispersion in this market.

Particularly, OTAs are a key element of the current scenario in the airline industry. As matter of fact, gross bookings for European OTAs accounted for 35\% of the online leisure and unmanaged business travel market in 2009 and were projected to expand their share of the online pie to $37 \%$ in 2012 (PhoCusWright, 2011). More importantly, OTAs have enormously contributed to the increase in the availability of information and the reduction of consumers' search costs in the travel industry. Therefore, these online agents have certainly played a relevant role in reducing flight price dispersion compared to the 'before internet' era. However, in the current scenario, in addition to the role of 'travel search engines' and the sale of packaged travels (e.g., flight + hotel), OTAs often offer distinct products even with regard to airline tickets by combining products of different airlines. This might result in different final prices across OTAs as well as between OTAs and airlines' direct channels. Therefore, overall, it can be argued that the type of online channel might add to the competition effect in determining price dispersion.

In this paper we use a panel dataset from the Italian airline market to study the role of competition and different types of online channels, in the emergence of price dispersion. 
Specifically, we investigate price dispersion in both airlines' direct channels (e.g., websites) and OTAs. This allows us to offer two important contributions to the existing literature on price dispersion. With regard to the role of competition, previous empirical studies focusing on the relationship between competition and price dispersion are restricted to the airlines' direct channels. As anticipated earlier, these studies empirical studies have provided contrasting indications. In fact, some studies have provided support to the brand loyalty effect finding evidence of higher price dispersion in presence of higher competition (Borenstein and Rose, 1994; Stavins, 2001; Giaume and Guillou, 2004). On the other hand, some recent studies have strongly corroborated the textbook theory by demonstrating a negative correlation between market competition and price dispersion (Gerardi and Shapiro, 2009; Gaggero and Piga, 2011). In fact, in their analyses, competition is shown to dampen the airlines' ability to price discriminate to exploit customers' heterogeneity in booking time preferences. In this case, the positive effect of competition identified by Borenstein and Rose (1994) is absent or at least outweighed by its traditionally negative influence on the ability to price over marginal costs. Therefore, such contrasting results suggest that the question of whether competition has a positive or negative influence on price dispersion is open more than ever. To contribute to the interesting dispute, our paper re-examines the unclear role of competition in price dispersion with novel data collected from different channels, namely direct and OTA channels. In addition, there are some further crucial differences between previous works and the present study. First and most important, we depart from previous studies which consider both leisure and business travellers, by focusing only one type of segment, i.e., the business segment, to be intended as the segment of customers who book airline tickets for reasons related to their job or business activity. Intuitively, in this case, the effect identified by Borenstein and Rose (1994) might be absent and, thus, the tendency to the 'law of one price' might be observed when competition becomes fiercer. But, still, one could argue that not all business travellers have the same willingness to pay or the same brand loyalty, e.g., managers of big vs. small companies. Therefore, this might still lead to some form of price discrimination also within the business segment, which might reverse the otherwise expected sign of the relationship between competition and price dispersion in presence of one segment. Second, compared to most of the previous studies (e.g., Borenstein and Rose, 1994; Gerardi and Shapiro, 2009) that consider tickets sold in a large time span and in different routes, we take a different approach. As a matter of fact, we construct $a d-h o c$ a dataset containing all the suitable products offered by major airlines and OTAs in the Italian market at different days before departure with regard to a representative potential business trip in different business routes. By doing so, similarly to Gaggero and Piga (2011), we can also study price dispersion from the supply side and how it may change when approaching the departure date. Essentially, our study can be viewed as an analysis of price dispersion at a micro-level, whereas most of previous studies look at the same issue from a macro-level perspective. The second important contribution is specifically related to the role of the type of online channels, direct vs. indirect, in price dispersion. Contrarily to the effect of competition, the relationship between price dispersion and the type of online channel has not received sufficient attention by researchers. There exist only a few closely related studies (Clemons et al., 2002; Lin et al., 2009), which have analysed whether and how prices levels change across several OTAs, showing that different OTAs offer tickets with substantially different prices. However, this stream does not investigate how price dispersion varies across different online channels, which is one of our goals. In addition, 
while these studies mostly restrict the comparison only to OTAs, our study investigates price dispersion across different both direct and indirect online airline channels. Therefore, we contribute to this stream by extending the lens of investigation to the relationship between price dispersion (rather than price levels) and the type of online channel. From a managerial perspective, comprehending how characteristics of the markets imply on pricing strategies, and in turn on price dispersion, is pivotal for the long-term viability of companies competing in online environments that are characterised by increasingly informed customers (Dominici, 2009a). As a matter of fact, a better understanding of the mechanisms behind online price formation and dispersion in the airline ticket market may enable managers to develop better business strategies. Our study aims to contribute to this purpose.

By way of anticipation, contrarily to what we would have expected given that our analysis focuses only on the business segment, our findings seem to be in line with results in Borenstein and Rose (1994), rather than with results in Gerardi and Shapiro (2009) and Gaggero and Piga (2011). That is, price dispersion is higher in routes where competition is higher even in presence of only one segment. Interestingly, as the theory alternative to the 'law of one price' connects such a phenomenon to the presence of customers with substantially different price sensitivity and brand loyalty, we can interpret our result as the evidence of significant heterogeneity in terms of price sensitivity at the micro-segment level, e.g., within the business segment, that airlines try to exploit via price discrimination. Moreover, with regard to the effect of the type of channel, our results show that price dispersion significantly differs across different channels. Specifically, as hypothesised, it is very likely that travellers would find higher price dispersion in the OTA rather than in the direct channels. This is because of the exclusive ability of OTAs of offering products that result from the combination of different airlines' products. It is noteworthy that all these results are shown to be robust across different models.

Our findings have several managerial implications for airline companies as well as OTAs. First, our results inform airlines and OTAs should expect that the 'law of one price' does not apply to the airline market. This implies that, on average, their profits are expected to significantly higher than those they would gain in presence of perfect competition. More interestingly, in terms of strategies, our findings imply both airlines and OTAs should take advantage from the demonstrated large heterogeneity in terms of price sensitivity at the micro-segment level, i.e., within the business segment, and profitably push the practice of price discrimination not only between leisure and business travellers but also among business travellers. While airlines can naturally price discriminate by setting different fares for business travellers displaying different price sensitivity, OTAs can still exploit this within-segment customer heterogeneity by influencing final prices in different ways (Bilotkach and Pejcinovska, 2012). As a matter of fact, OTAs can negotiate special deals with airlines based on long-term agreements (Shapiro, 2002; Perkins, 2011), but also because OTAs may arrange agreements with the owners of computerised reservation systems, (CRSs) in order to slightly modify fares displayed to customers in their own channel (The Economist, 2012). A further managerial implication of our study relates to the relationship between the channel where tickets are sold and price dispersion. Essentially, OTAs should be aware of the fact that they have more weapons to exploit the large customer heterogeneity in terms of price sensitivity and thus generate higher price dispersion. As a matter of fact, they can practice better fine-grained segmentation by combining flights of different airlines, a feature that is 
largely precluded to airlines. At the same time, airlines should try to counterbalance this peculiarity of OTAs by introducing exclusive fares in their own direct channels as well as by varying the fares more dynamically (especially in the last few days before flight departure) as compared with OTAs. Finally, our results also imply that consumers should expect larger price dispersion in OTA channel. Given the large amount of flights combinations at disposal of OTAs, the larger price dispersion may require greater effort and times to customers to find the best compromise price and ticket characteristics. To reduce such potential hassles, OTAs may find suitable to improve their sorting systems in order to provide a customised ranking of offers to consumers.

The remainder of this paper is organised as follows. We first introduce and discuss our hypotheses. Then, we describe the data, the variables and the econometric models utilised in this paper. We present our empirical findings and discuss some implications. Finally, we provide conclusions and future research directions.

\section{Theory and hypotheses}

\subsection{Competition effect}

Traditional microeconomic theory provides clear predictions for how the extent of competition should affect price dispersion. That is, price dispersion should decrease with competition due to the fact that firms lose their ability to price above their marginal costs. However, an alternative theory predicts an opposite effect of competition when firms can price discriminate between segments, which differ in their price sensitivity and brand loyalty (Borenstein, 1985; Holmes, 1989). In this case, higher competition intensity has the effect of reducing the prices offered to price sensitive and less brand loyal segments, while leaving the prices offered to less price sensitive and brand loyal segments. As a result, the increase in the price difference among these types of segments results in higher price dispersion. Due to the intrinsic characteristics illustrated above, the airline market has been a suitable business setting to test the predictions of the alternative theory. As a matter of fact, a number of empirical studies have tackled this issue. In full accordance with such theory, Borenstein and Rose (1994) found, in their seminal paper on US airline market, that routes with higher levels of competition were characterised by a greater degree of price dispersion. In the same vein, other studies have corroborated this view (Stavins, 2001; Giaume and Guillou, 2004). On the other hand, the textbook microeconomic theory has been shown to prevail in more recent studies (Gerardi and Shapiro, 2009; Gaggero and Piga, 2011). More importantly, Gerardi and Shapiro (2009) also explain that the findings in Borenstein and Rose (1994) may suffer from strong bias due to omitted variables. As a matter of fact, they show that when they use the same troublesome approach as in Borenstein and Rose (1994), they find the same result, whereas when they utilise econometric models where the issue of omitted variable bias is resolved or is irrelevant, they find estimates consistent with the traditional theoretical argument.

Overall, recent contributions seem to conclude that the traditional microeconomic explanation of the relationship between price dispersion and competition is quite solid, leaving no room for the alternative explanation. It would then appear quite reasonable to support the textbook theory, also in the light of the fact that we consider only one type of segment in our analysis, which, at a first blush, should reduce the magnitude of, or even 
eliminate, the brand loyalty effect. Therefore, the findings of recent contributions on one hand, and the absence of one of the two macro-segments typically identifiable in the travel industry on the other hand, should lead us to formulate the following:

$\mathrm{H}_{\mathrm{la}} \quad$ Competition negatively affects price dispersion.

However, for sake of completeness, we do not downplay a priori the theory supported by Borenstein and Rose (1994) among others as it might still emerge possibly because of the existence of price discrimination within the business segment. After all, common intuition suggests that there exists substantial heterogeneity within the business segment, the way we have defined it, i.e., people travelling for reasons related to their job or business activity. It is very likely, for instance, that managers or employees of large companies have a quite different purchasing behaviour if compared to employees of small businesses or government. Therefore, in presence of one macro-segment, i.e., the business segment, the theory supported by findings in Borenstein and Rose (1994) among others may still be at work even at the micro-segmentation level if there is a sufficiently high heterogeneity within the macro-segment. Thus, to maintain some a priori impartiality, we also present the hypothesis, which contrasts with the traditional textbook theory, that is:

$\mathrm{H}_{1 \mathrm{~b}} \quad$ Competition positively affects price dispersion.

\subsection{OTA versus direct channels}

From an operational viewpoint, an OTA works similarly to an airline company website. It collects information from the customer, principally departure and arrival cities (airports) and preferred flight times. In turn, the OTA takes this request and some further parameters set by the OTA and submits these to one or more computerised reservation systems (CRS), which searches for relevant flights from the collection of offerings from all airlines (Clemons et al., 2002). Afterwards, the OTA takes the collection of flights returned by the CRS, selects one or more flights for presentation to the customer, and sorts the final output (Clemons et al., 2002). When the customer chooses to purchase a ticket, the OTA processes the booking with the CRS and might or might receive a commission from the airline and/or from the customer in return depending on the adopted policy. Besides the possible commission, the major difference with an airline company website relates to which types of offerings are available in the two types of channel. The offerings displayed in an airline company website are only related to flights operated by the same company. On the other hand, OTAs can also offer products, which, for instance, result from combining flights of different service providers.

Despite the industry relevance of OTAs, the study of how price dispersion changes across different types of online channels has not received sufficient attention by researchers. As mentioned earlier, a few studies have looked at how price levels vary across OTAs (Clemons et al., 2002; Lin et al., 2009). In particular, Clemons et al. (2002) have analysed whether and how prices change across several OTAs in the US market, showing that different OTAs offer tickets with substantially different prices. They explained such result of high price dispersion as mainly driven by the fact that OTAs try to target different segments through product differentiation. For instance, some OTAs might choose to specialise in offering high quality tickets (e.g., best match with the requested departure and/or arrival time), whereas other OTAs might choose to focus on 
the best price deal. However, they also pointed out that, even after accounting for differences in ticket quality, ticket prices resulted in significant variations. In this regard, a possible explanation provided by the authors relates to the specific set of decision rules technologically implemented to identify which tickets will or will not be considered in the search and selection process. Similar results have been provided by Lin et al. (2009).

We differ from the above stream in that we examine how price dispersion rather than price levels varies across different online channels. In addition, our study focuses on the impact of OTAs relatively to the impact of airlines' direct channels. Specifically, our hypothesis on the current role of OTAs in price dispersion is grounded on two major points. The first intuitive point is that, although not properly being a reseller, each OTA might or might not charge its own fee, which will possibly add to the fare set by the given airline in the given route. Therefore, the final price charged to customers might be also affected by the policies adopted in determining the fee, thus leading a further source of price dispersion, which is naturally absent in the direct channels. Finally, we have already pointed out that, differently from airlines, OTAs have the ability of combining products of different brands to better match customers' requests and, thus, significantly increase the number of products available for customers. Intuitively, such proliferation of product offerings, which are not related to the same airlines, might result in higher price dispersion compared to direct channels. In fact, prices originally set by an airline for a given flight will be combined (e.g., algebraically summed) with prices set by other airlines for compatible flights, naturally leading to higher price dispersion.

The above major points, and especially the last one, seem to provide univocal indications with regard to the effect of OTAs in price dispersion, at least when compared to the effect of direct channels. We should arguably expect higher price dispersion in the OTA channel, rather than in airlines' direct channel. Thus, we can formulate the following:

$\mathrm{H}_{2}$ OTAs' websites are associated with higher price dispersion than airline companies' websites.

\section{Empirical analysis}

\subsection{Data}

To test the above hypotheses, we collected data regarding ticket offerings for round trip flights on 15 December 2010, from 22 major Italian airports to the airports of the two major business destinations in Italy, i.e., Milan and Rome ${ }^{1}$. This choice is consistent with our goal of restricting the analysis to consider one segment and, more precisely, the business segment. Here, we recall that the business segment is primarily intended to be the segment of customers who book airline tickets for reasons related to their job or business activity. Usually, this segment consists of travellers characterised by lower travel flexibility and, thus, higher willingness to pay (or lower price sensitivity) than leisure travellers (Chen et al., 2014). Furthermore, their stay in the city of destination is usually much shorter compared to leisure travellers (ISTAT, 2013). To some extent, also people travelling due to personal emergencies might be included in the business segment as they share the above fundamental characteristics. We collected the relevant data in the direct channel, i.e., the websites, of six major airlines operating in Italy and in three major 
OTAs. The six major airlines were chosen among the ten largest companies operating in Italy in terms of number of transported passengers ${ }^{2}$. However, as we focused on Italian routes, we removed some airlines for which Italian routes are not their core business, e.g., Lufthansa. Therefore, at the end, the airlines companies considered in our empirical analysis are: Alitalia, Ryanair, EasyJet, Meridiana, Windjet and Blue Express. As for the OTAs, we considered those very relevant in the Italian market in terms of market share at the time of the data collection. The major OTAs were: Expedia, Last Minute, eDreams and Volagratis ${ }^{3}$. However, we removed Last Minute as explicitly focused on offering last minute deals to leisure travellers. The ticket offerings were observed starting from 30 November 2010 to 14 December 2010, and more precisely, 15, 11, 6, 3 and 1 days before the departure date. This choice reflects the fact usually business travellers (including those consumers travelling due to personal emergencies) learn of the need of travel very close to the date of the service, contrarily to leisure travellers, who can, instead, carefully plan their travel. Since, for sake of convenience, we considered a round trip by the end of the day, we eliminated from the sample all the combinations with excessive flight duration, i.e., higher than four hours, or those preventing a 'feasible' stay in the final destination, i.e., lower than five hours. Our complete dataset comprises 14,554 observations of ticket offerings, well representing products appealing to consumers flying for business purposes.

\subsection{Variables}

We define a set of variables to test our hypotheses. Table 1 summarises the description and the modalities of all the variables, whereas Table 2 shows the relative descriptive statistics.

Table 1 Variables description

\begin{tabular}{|c|c|}
\hline Variables & Description \\
\hline $\begin{array}{l}\text { Gini index (dependent } \\
\text { variable) }\end{array}$ & $\begin{array}{l}\text { Continuous variable measuring the degree of price dispersion found } \\
\text { for route } i \text {, website } j \text { and at time } t \text {. }\end{array}$ \\
\hline Route HHI & $\begin{array}{l}\text { Continuous variable measuring the Herfindahl-Hirschman index of } \\
\text { route } i \text {. }\end{array}$ \\
\hline Channel type & $\begin{array}{l}\text { Binary variables equal to } 1 \text { if the observed pair route-website refers } \\
\text { to the OTA channel, } 0 \text { if it refers the airlines' direct channel. In } \\
\text { alternative to this variable, we considered nine binary variables, } \\
\text { namely WebAlitalia, WebMeridiana, WebEasyJet, WebRyanAir, } \\
\text { WebWindjet, WebBlueexpress, WebEdreams, WebExpedia and } \\
\text { WebVolaGratis, each equal to } 1 \text { if the observed pair route-website } \\
\text { refers to the specific website, } 0 \text { otherwise. }\end{array}$ \\
\hline Days before departure & $\begin{array}{l}\text { Integer variable indicating how many days before departure the } \\
\text { given product offerings were retrieved for a specific business route } i \\
\text { and website } j \text {. }\end{array}$ \\
\hline $\begin{array}{l}\text { Variance in the } \\
\text { presence of connecting } \\
\text { flights }\end{array}$ & $\begin{array}{l}\text { Continuous variable measuring the average variance in the presence } \\
\text { of connecting flights among all the product offerings related to route } \\
i \text {, website } j \text { and at time } t \text {. }\end{array}$ \\
\hline $\begin{array}{l}\text { Variance of departure } \\
\text { times }\end{array}$ & $\begin{array}{l}\text { Continuous variable measuring the average variance of departure } \\
\text { times among all the product offerings related to route } i \text {, website } j \text { and } \\
\text { at time } t \text {. }\end{array}$ \\
\hline
\end{tabular}


Table 1 Variables description (continued)

\begin{tabular}{ll}
\hline Instruments & \multicolumn{1}{c}{ Description } \\
\hline Total number of flights & $\begin{array}{l}\text { Integer variable measuring the total number of flights available in } \\
\text { route } i \text { in the time windows matching our requests. }\end{array}$ \\
Population & $\begin{array}{l}\text { Arithmetic mean of the population of metropolitan areas where } \\
\text { endpoints airports of a certain route } i \text { are located (source: ISTAT } \\
\text { several years). }\end{array}$ \\
& $\begin{array}{l}\text { Binary variable equal to } 1 \text { if for the given route } i \text { there exist a } \\
\text { product strongly substitutable, e.g., high speed train, to the airline } \\
\text { service, } 0 \text { otherwise. }\end{array}$ \\
Substitute & $\begin{array}{l}\text { Arithmetic mean of the number of passengers who have flown on a } \\
\text { certain route } i \text { (source: ENAC several years). }\end{array}$ \\
Route passengers & $\begin{array}{l}\text { Arithmetic mean of the per-capita GDP of the metropolitan areas } \\
\text { where endpoint airports within a certain route } i \text { are located (source: } \\
\text { Per-capita gross } \\
\text { ISTAT several years). }\end{array}$ \\
(GDP) &
\end{tabular}

Table 2 Descriptive statistics

\begin{tabular}{|c|c|c|c|c|c|}
\hline Variables & Mean & $\begin{array}{c}\text { Std. } \\
\text { deviation }\end{array}$ & Min & $\operatorname{Max}$ & $\begin{array}{l}\text { Frequency } \\
\text { (\% of } 1)\end{array}$ \\
\hline Gini index (dep. variable) & .689992 & .0813803 & 0 & .53207 & \\
\hline Route HHI & .696765 & .2245278 & .2727273 & 1 & \\
\hline Channel type & .7564197 & .4293999 & 0 & 1 & $75.64 \%$ \\
\hline Days before departure & 7.81438 & 5.182431 & 15 & 1 & \\
\hline $\begin{array}{l}\text { Variance in the presence of } \\
\text { connecting flights }\end{array}$ & .0775888 & .1485243 & 0 & 1 & \\
\hline Variance of departure times & .2795451 & .2638512 & 0 & 1.154701 & \\
\hline Total number of flights & 13.00073 & 8.992206 & 2 & 43 & \\
\hline \multicolumn{6}{|l|}{ Instruments } \\
\hline Population & $5,691,683$ & $1,218,986$ & $3,139,970$ & $7,679,444$ & \\
\hline Substitute & .3404255 & .4740262 & 0 & 1 & $34.04 \%$ \\
\hline Route passengers & $294,687.5$ & $233,337.8$ & 50,000 & $1,101,958$ & \\
\hline Per-capita GDP & $27,303.47$ & $2,998.502$ & 23,271 & $31,854.78$ & \\
\hline
\end{tabular}

First of all, for each unique combination of route, day of observation and website where the offering was available, we compute the Gini index, which is our dependent variable. As discussed by Gaggero and Piga (2011), there are a number of advantages in using the Gini coefficient to measure price dispersion. First, it has the desirable property of being scale invariant which allows the comparison of distributions having different magnitudes. Second, because the entire distribution of available fares is necessary to its calculation, it should be preferred to indexes such as the range, which only use two observations out of the entire sample, and are therefore sensible to outliers or might lead to the same value even in presence of different distributions. Finally, the Gini index or some of its transformations, e.g., the logarithm of the odds ratio, have been widely used to measure price dispersion in most of the previous works (Borenstein and Rose, 1994; Gerardi and Shapiro, 2009; Gaggero and Piga, 2011). Thus, adopting the same measure as a dependent variable allows us to be consistent and better connect our results with those of 
previous authors. However, it is noteworthy that we differ in that we compute the Gini index for each website due to the presence of the OTA channel, whereas in previous studies the Gini index has been computed for each airline company. The computation of Gini index for each unique combination of route, day of observation and website where the offering was available, obviously reduces the initial dataset so that the final dataset utilised to test our hypotheses comprises 1,363 observations, which are related to 376 unique pair's route-website and five days of observations. The reason behind the unbalanced nature of our panel dataset is essentially that some product offerings were no longer available in some website when approaching to the date of departure.

To the test of our hypotheses $H 1 a$ and $H 2 b$, we remain consistent with previous studies. Specifically, we utilise the well-known Herfindahl-Hirschman index (HHI) (referred to as route HHI) as a measure of competition in a given route. Actually, the route $H H I$ is more properly a measure of market concentration. However, it is straightforward that there exists an inverse relationship between market competition and concentration. That is, broadly speaking, a high concentration implies a low competition, whereas a low concentration is related a high competition. The route $H H I$ is calculated for each route and does not change across days of observation given our limited period of observation. Consistently with previous studies, it is computed as the sum of the squared market shares of each airline serving the given route. In turn, each airline's market share in a given route is computed as the total number of flights she operates in the route over the total number of flights operated by all airlines in the same route. As for each route we consider a typical daily round trip flight for business purposes, we include in the computation only those flights satisfying the above mentioned constraints.

To test our hypothesis H2, we simply introduce a dummy variable, namely channel type, which indicates whether the channel to which the observation relates is an OTA or the airline company website. The three OTAs in our sample seem to offer products from all the airlines with no big differences in terms of input quality. Therefore, we believe that the variable channel type is likely to well describe the relative impact of OTAs on price dispersion. Later, to evaluate any difference across OTAs and airline companies, we decompose this dummy in nine binary variables each indicating the specific website where the price offerings have been observed.

Finally, in addition to the two main variables we introduce several control variables, which are utilised in different models we test. Also in this case, we try to be consistent with previous studies. Specifically, most of our control variables are used in Borenstein and Rose (1994) and Gerardi and Shapiro (2009). We control for how many days before flight departure the given price is observed (namely, day before departure). This control variable appears important to us as it helps control for changes in price dispersion, which are likely to arise when approaching the date of departure. For instance, while most of the firms usually maintain very high prices when getting close the date of service, some firms may choose the different strategy of offering last minute deals to sell out excess capacity (Jerath et al., 2010). Such divergent pricing policies might result in an increase of price dispersion, which should be controlled for when studying the role of competition and OTAs in price dispersion. We also introduce two variables, namely variance of departure time and variance in the presence of connecting flights, which help control for price dispersion especially within a certain pair route-website. Specifically, they measure the variability in terms of departure time and presence of connecting flights among those offerings utilised to compute the Gini index for the given website, route and day of observation combination. Finally, we consider the total number of flights (total flights) in 
the given route, which should further help control for any possible carrier-route effect, i.e., accounting for some differences between pairs carrier-route ${ }^{4}$. As discussed later, in line with previous studies, we use also adopt the instrumental variables (IV) technique, which is needed due to potential concerns of endogeneity. For sake of length, the IVs are only described in Table 1.

\subsection{The econometric model}

The final sample is actually an unbalanced panel dataset with number of statistical units much larger than the observation period. When the number of statistical units is quite large compared to the observation period (i.e., number of days), three basic regression models, namely pooled OLS, fixed effects and random effects models, are usually suggested (Wooldridge, 2002). However, the fixed effects model is not appropriate in our setting because both variables of interest, e.g., market competition and type of channel, are time invariant. Therefore, we preliminarily compared pooled OLS and random effects models. The Breusch-Pagan Lagrange Multiplier test strongly indicated the presence of random effects. Therefore, we initially used the following base random effects to test our hypotheses (the subscripts $i, j$ and $t$ indicate route, website and day of observation, respectively):

$$
\begin{aligned}
\ln \left(\text { Odds Ratio Gini } i_{i j t}\right) & =\beta_{0}+\beta_{1} \text { Route HII }_{i}+\beta_{2} \text { Channel Type }_{j} \\
& +\beta_{k} \text { Controls }_{i j t}+\mu_{i j}+\varepsilon_{i j t},
\end{aligned}
$$

where in line with previous studies, we consider the logarithm of Gini odds ratio as the dependent variable (logarithmic forms are very common in literature, e.g., Roma et al., 2013) and included route $H_{H} I_{i}$ and channel type ${ }_{j}$, as our variables of interest as described above. Controls $s_{i j t}$ stands for the set of control variables, which we utilise under different model alternatives. $\mu_{i j}$ and $\varepsilon_{i j t}$ are the random effect and the error terms. Also, for all the non-binary variables (except for the case of variance of departure time and variance in the presence of connecting flights) we use the logarithmic transformation, which we omit to report in the above equation for sake of simplicity.

However, potential endogeneity concerns may arise with regard to the equation above. This is especially the case of the competition variable as largely discussed in Borenstein and Rose (1994) and Gerardi and Shapiro (2009). In fact, in general, higher price dispersion might make a route more appealing to firms, which would have a higher incentive to enter or switch from a route to another. This, in turn, would reflect in a change of the competitive structure in the long run. Essentially, price dispersion might influence the degree of competition in a route, thus leading to positive bias in the estimates of the competition variable coefficient. For such reason, these studies use the IV regression approach to take into account the potential endogeneity concern. In the same vein, we also perform several IV regression models in addition to the base model of random effects. However, it noteworthy to highlight one important difference between their studies and ours, which, in theory, might reduce the magnitude of endogeneity concerns in our data. In fact, the samples of Borenstein and Rose (1994), Gerardi and Shapiro (2009), and Gaggero and Piga (2011) are related to large time periods ranging from several months to even several years. In this case, the degree of competition in a certain route is very likely to vary with time as a of consequence of new airline entries or, for instance, due to the fact that some companies enlarge their offer operating more 
flights or abandon certain routes. As a matter of fact, in their samples, the degree of competition is a time-variant variable. We focus on a short period to capture price dispersion at the micro-level by investigating flight offerings during the days before departure. In such a short period, competition is obviously unlikely to vary: in our sample the degree competition of competition is, in fact, a time-invariant variable. In our opinion, the fact that competition varies only across routes, while price dispersion is a time-variant dependent variable should weaken the magnitude of potential endogeneity concern, if any. This is because the long run effect of price dispersion on the competitive structure should be absent or limited. Nevertheless, to be safe and, at the same time, increase the reliability of our findings, we perform IV regression models and present them together with the base random effect model in the next sub-section.

\subsection{Results and discussion}

The results of our empirical analysis are presented on Tables 3 and 4. Table 3 presents the results under different models without the use of the IV approach, whereas Table 4 reports the results under different models with the use of IV approach. In both Tables 3 and 4, unless explicitly stated, different columns refer to models where different control variables are utilised. As all results are shown to be quite robust across various models, we generally discuss the main insights delivered by them. Specifically, with regard to the role of competition in influencing price dispersion, we have formulated two opposite hypotheses ( $\mathrm{Hla}$ and $\mathrm{H} 1 \mathrm{~b}$, respectively), each consistent with one of the two main microeconomic theories available to explain the relationship between market competition and price dispersion. However, given that we focused on products typically offered to business travellers, common intuition would have suggested the dominance of the textbook theory, i.e., negative effect of competition on price dispersion, over the theoretical argument of the brand loyalty effect. Quite surprisingly, our findings seem to be, instead, in line with results in Borenstein and Rose (1994), while being in contrast with those in Gerardi and Shapiro (2009) and Gaggero and Piga (2011), which support the textbook theory. Thus, price dispersion is higher, rather than being lower, in routes where competition is higher even in presence of only one segment. Therefore, our result might be interpreted as the evidence of significant heterogeneity within the business segment that airlines exploit via price discrimination. Essentially, the interesting implication of our finding is that the argument supported by Borenstein and Rose (1994) that competition has impact only on lowly valuable customers, while having little effect on highly valuable customers, might apply not only to a macro-segmentation level, i.e., business vs. leisure travellers, but also to a micro-segmentation level, e.g., within the business segment. After all, it is quite reasonable that managers or employees of large companies have lower price sensitivity, and even higher loyalty to a few high-end brands, than managers or employees of small businesses or medium-low level government officials, who might need to search for a fair price due to budget and rule constraints. Competition produces effects only on the latter type of business travellers so that high price dispersion will be likely to arise in highly competitive markets. This result appears to be robust under different models with and without using IVs. Therefore, also in the light of the findings obtained by previous results, our analysis confirms that both traditional and alternative theories can apply to the airline industry. The dominance of one effect over the other will eventually determine the sign of the relationship between competition and price dispersion. Perhaps, by way of conjecture, when competition is 
very fierce the traditional effect is likely to be dominant, whereas the brand loyalty effect might outweigh the former effect in presence of mild competition. In this regard, it is interesting to note that the results of Gerardi and Shapiro (2009) and Gaggero and Piga (2011) are found in markets (US market from 1993 to 2006 and UK market in 2006, respectively) which appear overall more competitive than the market analysed by Borenstein and Rose (US market in 1986) and that analysed in the present paper (Italian market in 2010). This might sound as a reasonable explanation of the different results.

Table 3 Results under different models with no IVs

\begin{tabular}{|c|c|c|c|c|}
\hline & (1) & (2) & (3) & (4) \\
\hline Variables & $\begin{array}{c}\text { Random effects } \\
1\end{array}$ & $\begin{array}{l}\text { Random effects } \\
2\end{array}$ & $\begin{array}{c}\text { Random effects } \\
3\end{array}$ & $\begin{array}{l}\text { Random effects } \\
4 \text { (with website } \\
\text { variables) }\end{array}$ \\
\hline Route HHI (ln) & $\begin{array}{c}-.0879141^{* * *} \\
(.0236515)\end{array}$ & $\begin{array}{c}-.0967533 * * * \\
(.0188792)\end{array}$ & $\begin{array}{c}-.0885918^{* * *} \\
(.0188161)\end{array}$ & $\begin{array}{c}-.1189763 * * * \\
\quad(.0189959)\end{array}$ \\
\hline Channel type & $\begin{array}{l}.0275976^{* *} \\
(.0089264)\end{array}$ & $\begin{array}{l}.0164515^{*} \\
(.0070444)\end{array}$ & $\begin{array}{c}.0188356 * * \\
(.007096)\end{array}$ & \\
\hline $\begin{array}{l}\text { Days before departure } \\
(\ln )\end{array}$ & $\begin{array}{c}.0003896 \\
(.0025193)\end{array}$ & $\begin{array}{c}-.0091797 * * * \\
(.0020759)\end{array}$ & $\begin{array}{c}-.0087467 * * * \\
(.0020745)\end{array}$ & $\begin{array}{c}-.0097287 * * * \\
(.0021035)\end{array}$ \\
\hline $\begin{array}{l}\text { Variance in the presence } \\
\text { of connecting flights }\end{array}$ & & $\begin{array}{l}.2952023 * * * \\
(.0307507)\end{array}$ & $\begin{array}{l}.2949769 * * * \\
(.0305556)\end{array}$ & $\begin{array}{l}.2845574 * * * \\
(.0306463)\end{array}$ \\
\hline $\begin{array}{l}\text { Variance of departure } \\
\text { times }\end{array}$ & & $\begin{array}{l}.08002 * * * \\
(.0098378)\end{array}$ & $\begin{array}{c}.0714558^{* * *} \\
(.0105098)\end{array}$ & $\begin{array}{c}.0821923 * * * \\
(.0100346)\end{array}$ \\
\hline $\begin{array}{l}\text { Total number of flights } \\
\text { (ln) }\end{array}$ & & & $\begin{array}{l}.013515^{* * *} \\
(.0035434)\end{array}$ & \\
\hline WebEdreams & & & & $\begin{array}{l}.0125174 \\
(.0106172)\end{array}$ \\
\hline WebExpedia & & & & $\begin{array}{l}-.0047484 \\
(.0104849)\end{array}$ \\
\hline WebVolaGratis & & & & $\begin{array}{l}-.011366 \\
(.0100939)\end{array}$ \\
\hline WebRyanAir & & & & $\begin{array}{c}-.037956 * * * \\
(.0111532)\end{array}$ \\
\hline WebMeridiana & & & & $\begin{array}{r}-.04142 * * * \\
(.0101501)\end{array}$ \\
\hline WebEasyJet & & & & $\begin{array}{c}-.0611875^{* * *} \\
(.0128175)\end{array}$ \\
\hline WebWindjet & & & & $\begin{array}{c}-.067256^{* * * *} \\
(.0143109)\end{array}$ \\
\hline WebBlueexpress & & & & $\begin{array}{c}-.0486355^{* * * *} \\
(.0128922)\end{array}$ \\
\hline
\end{tabular}

Notes: Standard errors in parentheses $-{ }^{\dagger} p<0.10,{ }^{*} p<0.05,{ }^{* *} p<0.01,{ }^{* * *} p<0.001$. We use the logarithmic transformation for all independent and IV variables except dummies, Variance in the presence of connecting flights and variance of departure times. 
Table 3 Results under different models with no IVs (constant)

\begin{tabular}{|c|c|c|c|c|}
\hline & (1) & (2) & (3) & (4) \\
\hline Variables & $\begin{array}{c}\text { Random effects } \\
1\end{array}$ & $\begin{array}{l}\text { Random effects } \\
2\end{array}$ & $\begin{array}{c}\text { Random effects } \\
3\end{array}$ & $\begin{array}{c}\text { Random effects } \\
4 \text { (with website } \\
\text { variables) }\end{array}$ \\
\hline Constant & $\begin{array}{l}.09725^{* * *} \\
(.0157845)\end{array}$ & $\begin{array}{c}.0828314 * * * \\
(.012644)\end{array}$ & $\begin{array}{l}.047386^{* *} \\
(.0157177)\end{array}$ & $\begin{array}{c}.1130728^{* * * *} \\
(.011451)\end{array}$ \\
\hline N. observations & 1363 & 1363 & 1363 & 1363 \\
\hline Wald test $\left(\mathrm{p}>\operatorname{chi}^{\wedge} 2\right)$ & 0.0001 & 0.0000 & 0.0000 & 0.0000 \\
\hline \multicolumn{5}{|l|}{$\mathrm{R}^{\wedge} 2$} \\
\hline Within & 0.0000 & 0.2289 & 0.2299 & 0.2280 \\
\hline Between & 0.0357 & 0.4226 & 0.4344 & 0.4605 \\
\hline Overall & 0.0435 & 0.3484 & 0.3549 & 0.3740 \\
\hline
\end{tabular}

Notes: Standard errors in parentheses $-{ }^{\dagger} p<0.10,{ }^{*} p<0.05,{ }^{* *} p<0.01,{ }^{* * *} p<0.001$. We use the logarithmic transformation for all independent and IV variables except dummies, Variance in the presence of connecting flights and variance of departure times.

Table 4 Results under different models with IVs

\begin{tabular}{lccc}
\hline \multirow{2}{*}{ Variables } & $(1)$ & $(2)$ & $(3)$ \\
\cline { 2 - 4 } & IV reg re 1 & IV reg re 2 & IV reg re 3 \\
\hline Route HHI (ln) & $-.2173862^{* *}$ & $-.1477435^{* *}$ & $-.1037849^{\dagger}$ \\
& $(.0711253)$ & $(.0554892)$ & $(.056042)$ \\
Channel type & $.02914^{* * *}$ & $.0171786^{*}$ & $.0195254^{* *}$ \\
& $(.0087122)$ & $(.0067261)$ & $(.0066573)$ \\
Days before departure $(\mathrm{ln})$ & .0002143 & $-.0092137^{* * *}$ & $-.0086928^{* * *}$ \\
& $(.0022556)$ & $(.0020219)$ & $(.0020228)$ \\
Variance in the presence & & $.2932991^{* * *}$ & $.2941614^{* * *}$ \\
of connecting flights & & $(.0156914)$ & $(.0156018)$ \\
Variance of departure & & $.0812913^{* * *}$ & $.0696456^{* * *}$ \\
times & & $(.0094838)$ & $(.010008)$ \\
Total number of flights & & & $.016685^{* * *}$ \\
(ln) & & & $(.0047409)$ \\
Constant & $.1635369^{* * *}$ & $.108551^{* * *}$ & .0478978 \\
& $.0372967)$ & $(.0286107)$ & $(.0330066)$ \\
N. observations & 1363 & 1363 & 1363 \\
Wald test $(\mathrm{p}>$ chi^2) & 0.0004 & 0.0000 & 0.0000 \\
\hline
\end{tabular}

Notes: Standard errors in parentheses $-{ }^{\dagger} p<0.10,{ }^{*} p<0.05,{ }^{*} p<0.01, * * * p<0.001$.

We use the logarithmic transformation for all independent and IV variables except dummies, Variance in the presence of connecting flights and Variance of departure times. 
Table 4 Results under different models with IVs (continued)

\begin{tabular}{lccc}
\hline Variables & $(1)$ & $(2)$ & $(3)$ \\
\cline { 2 - 4 } & IV reg re 1 & IV reg re 2 & IV reg re 3 \\
\hline $\mathrm{R}^{\wedge} 2$ & & & \\
Within & 0.0000 & 0.2286 & 0.2300 \\
Between & 0.0329 & 0.4091 & 0.4307 \\
Overall & 0.0335 & 0.3444 & 0.3539 \\
\hline
\end{tabular}

Notes: Standard errors in parentheses $-{ }^{\dagger} p<0.10,{ }^{*} p<0.05, * * p<0.01, * * * p<0.001$.

We use the logarithmic transformation for all independent and IV variables except dummies, Variance in the presence of connecting flights and Variance of departure times.

As for the role of OTAs relatively to direct channels, Tables 3 and 4 shows that there is a significant effect of the channel type. That is, hypothesis H2 is largely confirmed. Specifically, compared to airlines' direct channels, OTAs are associated with much higher price dispersion. As Clemons et al. (2002) have argued, OTA channels are characterised by high price variability, which is mainly driven by the fact that different OTAs might differentiate by specialising on different price/quality tradeoffs. However, although demonstrating the high price dispersion arising in these channels, their result does not provide an explanation with regard to the comparison with airlines' direct channels. Also, at least with regard to the OTAs in our sample, it seems that they sell products from all the airlines with no specific focus on certain tradeoffs. Therefore, although being plausible, we tend to exclude the role of different tradeoffs specialisation as the major source of higher price dispersion in the OTA channel. Also based on the results, we also tend not to support the argument, which would suggest the commission each OTA sets and charge to final customers as the major driver of the result. Rather, we argue that the intuition behind our result is that OTAs are able to offer products combining products from different airlines, which is impossible to airlines in their own direct channels. The combination of product offerings deriving from different service providers, which is then unique to the OTA channel, increases price dispersion. Therefore, the main implication of our novel finding is that when considering both direct and OTA channels, travellers (from the business segment, in this case) should certainly expect higher price dispersion in the latter type of channel. By substituting the channel type dummy with nine dummies each indicating the website to which the given observation refers we are able to find that there is no significant evidence that OTAs are associated with higher price dispersion than the major Italian airline company, namely Alitalia. Furthermore, as expected, most of the airlines show significantly lower price dispersion than the major Italian airline company. A representative example of this kind of analysis is reported in Table 3 (fourth column). To some extent, the overall picture composed by our results suggests the presence of both different inter-channel and inter-firm price dispersion.

Finally, with regard to the control variables, from Tables 3 and 4, note that they have all the expected sign. In particular, it turns out to be interesting that price dispersion actually decreases when approaching the departure data. The level of uncertainty that characterises the demand in this industry decreases by getting closer and closer to the date of departure. Therefore, this would imply by itself the homogenisation of prices. However, the results suggest that the fact firms may choose among different pricing 
strategies, e.g., last minute deals vs. very high prices, when dealing with excess capacity or excess demand is the driver of the observed result.

\section{Managerial implications and conclusions}

The airline industry has been studied by economists and management researchers from numerous perspectives. Particular attention has been reserved to the issue of price dispersion as many have highlighted that, especially after internet introduction, markets characterised by homogeneous products and, thus, intrinsically high level of competition, would have reached the equilibrium state of the 'law of one price' as firms would have lost their ability to price above marginal costs. However, other theorists have predicted that, in the airline market, a positive effect of competition on price dispersion would have been possible given the existence of group of customers with very distinct price sensitivity and brand loyalty, i.e., leisure vs. business travellers. Both traditional and alternative theories have been tested with contrasting findings. In this regard, based on a novel dataset from the Italian market, this paper has contributed to show how, in spite of the fact that some recent papers questions the alternative effect of competition suggested by Borenstein and Rose (1994) among the others, such effect might actually dominate the traditional one. In fact it seems to be valid not only at a level of macro-segmentation, i.e., leisure vs. business travellers, but also at a level of micro-segmentation, e.g., within a macro-segment. As a matter of fact, we have provided evidence that price dispersion increases with competition also when only the business segment is considered. In the light of the brand loyalty effect, this suggests the idea of high heterogeneity within the business segment that airlines are likely to exploit via price discrimination. Such discriminatory pricing practice is amplified (and not reduced) when competition is high as the fares offered to less price sensitive and loyal customers remains high, while those offered to price sensitive and less loyal customers drastically diminish. We have also studied how price dispersion in the airline market also depends on the type of online channel. The empirical analysis has largely confirmed our hypothesis. The higher price dispersion associated with OTAs compared to direct channels arises because of their ability of combining products from products of different airlines. This is indeed a prerogative precluded to airlines.

Based on our results we suggest that both airlines and OTAs should significantly push the practice of price discrimination not only between business and leisure travellers, but also within the business segment. Our study also suggests that OTAs should take advantage of their unique feature of combining flights from different airlines as this feature allows them to better segment and price discriminate among customers. At the same time, airlines should try to counterbalance this advantage of OTAs by introducing more exclusive fares in their own direct channels as well as by varying the fares more dynamically (especially in the last few days before flight departure) as compared with OTAs. An additional implication of our analysis is that because consumers are more likely to expect higher price dispersion in their channels and because consumers do not want to face high 'search costs', OTAs should consider the opportunity to improve their sorting algorithms and push toward more customised rankings of the multitude of offerings to consumers.

Therefore, from a more general point of view, a better understanding of the features that cause price dispersion grants key information to managers developing and 
implementing pricing strategies. Indeed, this study can be useful to marketing managers in developing pricing strategies by supporting them to better evaluate possible competitive responses to market changes. Moreover, to better understand the effects of competition on price dispersion improving the evaluation of local market attractiveness is particularly useful to managers of companies that want to penetrate new markets and need to know the effect of price dispersion on the market profitability. It is also pivotal to evaluate the effects of strategic moves for managers of companies operating in a market that must face the new entries.

There are several opportunities for building upon this study and thus overcome some of its actual limitations. First, although the results obtained with our sample are shown to be quite robust and are also derived taking into account the potential endogeneity concern, there is still room for improvement. Specifically, we could consider further models that overcome the limit of application of fixed effects model in our setting where the two variables of interest are time-invariant. For instance, a further check could be done via the Hausman-Taylor regression, although this would imply different assumptions compared to random effect model. Second, even with regard to the random effect model, IVs different from those suggested by Borenstein and Rose (1994) and Gerardi and Shapiro (2009) and already adopted in this paper, might be utilised in the future. Also more recently, some studies have considered inverted U-shaped behaviour of price dispersion with competition (e.g., Dai et al., 2014; Roma et al., 2014). Third, from a broader perspective, collecting data samples relative to business trips with extended stay (i.e., more than one day) or even data from the leisure segment could really help increase the robustness of the main insights provided in this study. Fourth, to the best of our knowledge, all the analyses regarding price dispersion in the airline market have been focusing on national markets. In particular in this study we have focused on the Italian market. It would be interesting to re-examine the theories in the international markets. In such case, for instance, the role of international alliances and code sharing might be relevant in terms of price dispersion. Fifth, due to the large amount of data, which would be considered, taking the perspective of international markets could also help verify our conjecture that the traditional effect of competition is likely to prevail in presence of fierce competition, otherwise the brand loyalty effect will dominate. Sixth, it would be important to analyse the relationship between price dispersion and customer satisfaction in the OTA channel. Finally, a very interesting research direction is the study of price dispersion in another important sub-sector of the travel industry, i.e., the hotel industry, where OTAs are supposed to have even larger impact.

\section{References}

Baye, M.R., Morgan, J. and Scholten, P. (2004) 'Price dispersion in the small and in the large: evidence from an internet price comparison site', The Journal of Industrial Economics, Vol. 52, No. 4, pp.463-496.

Bilotkach, V. and Pejcinovska, M. (2012) 'Distribution of airline tickets: a tale of two market structures', in Peoples, J. (Ed.): Pricing Behavior and Non-Price Characteristics in the Airline Industry (Advances in Airline Economics), Vol. 3, Ch. 5, pp.107-138, Emerald Group Publishing Limited, UK.

Borenstein, S. (1985) 'Price discrimination in free-entry markets', RAND Journal of Economics Vol. 16, No. 3, pp.380-397. 
Borenstein, S. and Rose, N.L. (1994) 'Competition and price dispersion in the U.S. airline industry', Journal of Political Economy, Vol. 102, No. 4, pp.653-683.

Chen, R.R., Gal-Or, E. and Roma, P. (2014) 'Opaque distribution channels for competing service providers: posted price vs. name-your-own-price mechanisms', Operations Research, Vol. 62, No. 4, pp.733-750.

Clemons, E.K., Hann, I-H. and Hitt, L.M. (2002) 'Price dispersion and differentiation in online travel: an empirical investigation', Management Science, Vol. 48, No. 4, pp.534-549.

Dai, M., Liu, Q. and Serfes, K. (2014) 'Is the effect of competition on price dispersion non-monotonic? Evidence from the U.S. airline industry', The Review of Economics and Statistics, Vol. 96, No. 1, pp.161-170.

Dominici, G. (2009a) E-marketing. analisi dei cambiamenti dai modelli di business al mix operative, Franco Angeli, Italy, Milan.

Dominici, G. (2009b) 'From marketing mix to e-marketing mix: a literature overview and classification', International Journal of Business Management, Vol. 4, No. 9, pp.17-24.

European Commission (2011) Case No Comp/M.6164 - Axa/Permira/Opodo/Go Voyages/Edreams [online] http://ec.europa.eu/competition/mergers/cases/decisions/m6163_20110530_20310_ 1852583_EN.pdf (accessed April 2015).

Gaggero, A.A. and Piga, C.A. (2011) 'Airline market power and intertemporal price dispersion', The Journal of Industrial Economics, Vol. 59, No. 4, pp.552-577.

Gailey, E.D., Dixit, A., Whipple, T.W. and Javalgi, R. (2012) 'Price dispersion in the airline industry: a conceptual framework and empirical analysis', American Journal of Management, Vol. 12, No. 1, pp.92-107.

Gerardi, K.S. and Shapiro, A.H. (2009) 'Does competition reduce price dispersion? New evidence from the airline industry', Journal of Political Economy, Vol. 117, No. 1, pp.1-37.

Giaume, S. and Guillou, S. (2004) 'Price discrimination and concentration in European airline markets', Journal of Air Transport Management, Vol. 10, No. 5, pp.305-310.

Holmes, T. (1989) 'The effects of third-degree price discrimination in oligopoly', American Economic Review, Vol. 79, No. 1, pp.244-250.

ISTAT (2013) Viaggi e vacanze in Italia e all'estero, Statistiche Report, Istat, Rome.

Jerath, K., Netessine, S. and Veeraraghavan, S.K. (2010) 'Revenue management with strategic customers: last-minute selling and opaque selling', Management Science, Vol. 56, No. 3, pp.430-448.

Lin, P-C., Chen, C-C. and Song, M-H. (2009) 'Price dispersion of online air tickets for short distance international routes', The Service Industries Journal, Vol. 29, No. 11, pp.1597-1613.

Orlov, E. (2011) 'How does the internet influence price dispersion? Evidence from the airline industry', The Journal of Industrial Economics, Vol. 49, No. 1, pp.21-37.

Perkins, E. (2011) Do Consumers Lose When Airlines and OTAs Fight?, 9 January [online] http://www.insights.org.uk/articleitem.aspx?title=The+Changing + Face + of + Airline + Distributi on (accessed April 2015).

PhoCusWright (2011) European Online Travel Agencies: Navigating New Challenges, October [online] http://www.sabretravelnetwork.com/images/uploads/collateral/TNEMEA-11-14712 _Online_White_Paper_LR.pdf (accessed April 2015).

Roma, P., Di Martino, G. and Perrone, G. (2013) 'What to show on the wine labels: a hedonic analysis of price drivers of Sicilian wines', Applied Economics, Vol. 45, No. 19, pp.2765-2778.

Roma, P., Zambuto, F. and Perrone, G. (2014) 'Price dispersion, competition, and the role of online travel agents: evidence from business routes in the Italian airline market', Transportation Research Part E, Vol. 69, No. C, pp.146-159.

Shapiro, M. (2002) 'The sum of all fares', The Washington Post, 28 July [online] $\mathrm{http} / / / \mathrm{www}$.washingtonpost.com/wp-dyn/articles/A6387-2002Jul26.html (accessed April 2015). 
Stavins, J. (2001) 'Price discrimination in the airline market: the effect of market concentration', The Review of Economics and Statistics, Vol. 83, No. 1, pp.200-202.

The Economist (2012) The Ineluctable Middlemen, 25 August [online] http://www.economist.com/node/21560866 (accessed April 2015).

Wooldridge, J.M. (2002) Econometric Analysis of Cross-Section and Panel Data, The MIT Press, Cambridge.

\section{Notes}

1 Based on data made by Assaeroporti (the Italian Airport Association) on its website (http://www.assaeroporti.it), at the time of data collection, i.e., in 2010, the 23 major Italian airports by number of passengers were: Fiumicino (Rome), Malpensa (Milan), Linate (Milan), Orio al Serio (Milan), Venice, Catania, Naples, Ciampino (Rome), Bologna, Palermo, Pisa, Cagliari, Turin, Verona, Bari, Treviso, Olbia, Florence, Lamezia Terme, Alghero, Genoa, Brindisi and Trapani. Interestingly, we were not able to find any offer of flights departing from the airport of Treviso, which matched our requests and constraints. Therefore, this airport was removed to the purpose of our analysis, thus reducing the number of airports to 22 . Furthermore, it appears quite intuitive that given that we considered only airports in Milan and Rome as business destinations for our analysis, some routes were a priori excluded due to the clear proximity between some cities, e.g., Turin and Milan.

2 Updated information can be for instance retrieved by ENAC (Italian Civil Aviation Authority) website (http://www.enac.gov.it/Home/).

3 Updated information can be retrieved for instance by the document made available by the European Commission (http://ec.europa.eu/competition/mergers/cases/decisions/m6163 $20110530 \quad 20310 \quad 1852583$ EN.pdf) with regard to the merger request submitted to the European Commission by Opodo, GO Voyages and eDreams.

4 Initially we also considered airlines' market shares in the formulation of the econometric model. However, these variables turned out to be very highly correlated with the HHI. Also the total number of flights is mathematically linked to the HHI, even though not showing the same high degree of correlation. Furthermore, as shown later, we control for any effect specific to the pair route-website using the random effects model. Thus, similar to Gerardi and Shapiro (2009) (although they use fixed effects model), we might not need to include such variable, which might create collinearity. Nevertheless, we include it in some of the models we present, showing that our results are qualitatively unchanged. 